\title{
Economic Efficiency Analysis of Tourism Poverty Alleviation in Wuling Mountain Area of Guizhou
}

\author{
Hui Sheng \\ School of Finance \\ Guizhou University of Finance and Economics \\ Guiyang, China \\ 1206424342@qq.com
}

\begin{abstract}
Tourism poverty alleviation is an important part of poverty alleviation. In order to investigate the performance of tourism poverty alleviation, this paper selected 12 districts in Wuling Mountain Area of Guizhou as research objects, and then built DEA model to measure the total efficiency, pure technical efficiency and scale efficiency of tourism poverty alleviation. The results show that tourism development had a certain effect on economic poverty alleviation and the efficiency of tourism poverty alleviation in Wuling Mountain Area of Guizhou was better than the middle level. However, the tourism poverty alleviation among districts proceed unevenly with some districts lagging behind. Judging from the effect of decomposition efficiency on total efficiency, pure technical efficiency contributed more to total efficiency. Therefore, this paper proposed to establish a training system for tourism practitioners and optimize the management system so as to improve the efficiency of tourism poverty alleviation.
\end{abstract}

Keywords-tourism poverty alleviation; DEA; efficiency decomposition; Wuling Mountain Area of Guizhou

\section{INTRODUCTION}

As a global problem, poverty still hinders the development of the whole society. However, tourism, as a sunrise industry and a green industry, can play a big role in poverty alleviation. The foreign countries have established tourism poverty alleviation system early. In the late 1990s, researchers have tried to connect tourism development with poverty reduction. In 1999, the Department for International Development (DFID) proposed the PPT (Pro-Poor Tourism), which is "tourism for the development of the poor" [1]. Since then, the community has conducted researches on tourism poverty alleviation. In China, tourism poverty alleviation has been promoted as development experience and then more and more domestic scholars have attached great importance to tourism poverty alleviation. For example, Huang Meifang and $\mathrm{Yu}$ Chunyu (2014) evaluated the performance of national tourism poverty alleviation in Longsheng County of Guangxi Province according to the analytic hierarchy process, Delphi method and quantitative model method [2]. Feng Weilin and Tao Congchong (2017), based on the sample survey data of poverty-stricken population in Wuling Mountain Area of Chongqing, evaluated quantitatively the performance of tourism poverty alleviation in Southwest China [3]. Huang Yuanji (2017) used DEA to evaluate the performance of tourism poverty alleviation in the Wuling Mountain Area of Hunan [4].
The previous researches have carried out relevant argumentation and analysis on the economic benefits of tourism poverty alleviation, which provides a sufficient theoretical basis for the research of this paper. However, due to the vast territory of China, some areas have yet to be investigated. The Wuling Mountain Area in Guizhou which is badly poverty-stricken and has abundant tourism resources has been scarcely researched on tourism poverty alleviation efficiency over the years. Therefore, based on the original data of the poor districts of Wuling Mountain Area of Guizhou from 2012 to 2014, this paper used the DEA model to make evaluations on the economic benefits of tourism poverty alleviation in the region, and proposed corresponding policy recommendations.

\section{RESEARCH DESIGN}

\section{A. Research methods}

DEA (Data Envelope Analysis) is mainly used to calculate the relative effectiveness of homogeneous decision-making units (DMU) converting multiple inputs into multiple outputs by comparing the degree that the decision-making units deviate from the frontier [5]. It is equivalent to the Pareto efficiency (or non-dominated solution) of the multi-objective programming problem. According to the basic principle of DEA, the efficiency of tourism poverty alleviation should take the district as the actual decision-making unit to research the driving roll of tourism to economy.

DEA can be assorted into two categories according to the scale returns. One is the CCR model under the constant returns to scale (CRS) and the other is the BCC model with the variable return to scale (VRS) [6]. The CCR model mainly measures the total efficiency of the decision-making unit. The total efficiency can be decomposed into scale efficiency and pure technical efficiency. Both scale efficiency and pure technical efficiency can be measured by the BCC model. The expressions of the CCR model and the BCC model are as follows:

$$
\begin{aligned}
& \text { CCR model } \\
& \left\{\begin{array}{l}
\min \theta \theta \text { unlimited } \\
\text { s.t. } \sum_{j=1}^{n} \lambda x_{i j}+S_{I}^{-}=\theta x_{i 0} \\
\sum_{j=1}^{n} \lambda_{j} y_{r j}-S_{r}^{+}=y_{r 0} \\
S_{I}^{-} \geq 0, S_{r}^{+} \geq 0, \lambda_{j} \geq 0, j=1,2, \ldots, n
\end{array}\right.
\end{aligned}
$$




\section{BCC model}

$$
\left\{\begin{array}{l}
\min \theta \quad \theta \text { unlimited } \\
\text { s.t. } \sum_{j=1}^{n} \lambda x_{i j}+S_{I}^{-}=\theta x_{i 0} \\
\sum_{j=1}^{n} \lambda_{j} y_{r j}-S_{r}^{+}=y_{r 0} \\
\sum_{j=1}^{n} \lambda_{j}=1 \\
S_{I}^{-} \geq 0, S_{r}^{+} \geq 0, \lambda_{j} \geq 0, j=1,2, \ldots, n
\end{array}\right.
$$

In equations (1) and (2), $\mathrm{x}_{\mathrm{ij}}$ represents the total amount of the ith input of the jth DMU, and $\mathrm{y}_{\mathrm{rj}}$ represents the total output of the rth type of the jth DMU. $\theta$ is the total efficiency of the target DMU. $\lambda_{\mathrm{j}}$ is the weight variable. $S_{I}^{-}$or $S_{r}^{+}$is the slack variable of input or output. If the optimal solution is that $\theta^{*}=1$ and $S_{I}^{-}=S_{r}^{+}=0$, the DMU is DEA efficient, indicating that the efficiency of resource distribution is optimized to the best. If the optimal solution is that $\theta^{*}=1$, the DMU has weak DEA efficiency. If the optimal solution is that $\theta^{*}<1$, the DMU is not DEA efficient.

\section{B. Object selection}

This paper takes the Wuling Mountain Area of Guizhou as the research object and selects 12 districts which have tourist attractions of Grade 3A or above as the DMU because these attractions have better construction and more convenient transportation. Tourism in these districts play an important role in the development of economy. The selected districts and scenic spots are listed in Table 1.

TABLE I. DIST RICTS AND REPRESENT ATIVE SCENIC SPOTS

\begin{tabular}{|c|c|c|}
\hline City & Ddistrict & Tourist attractions of Grade 3A or above \\
\hline \multirow{5}{*}{ Tongren } & Shiqian & Wude-the Land of Peach Blossoms, The Ancient Upstairs Village, Fodingshan Mountain \\
\cline { 2 - 3 } & Bijiang & Ming Paradise \\
\cline { 2 - 3 } & Sinan & Haojiawan Tourist site, Tenglong Gorge, Thermal spring\& stone forest scenic spot \\
\cline { 2 - 3 } & Wanshan & Wanshan Mine Park \\
\cline { 2 - 3 } & Songtao & Guizhou Miao Wangcheng \\
\cline { 2 - 3 } & Yuping & Fish and grain agricultural park, Zhaisha Dongzhai, Mountain Fanjing, Yamu Gou, Yun She \\
\cline { 2 - 3 } & Jiangkou & Gaojia Wan high efficiency agriculture scenic spot \\
\cline { 2 - 3 } & Dejiang & Nanzhuang \\
\cline { 2 - 3 } & Yanhe & Tuanlong \\
\cline { 2 - 3 } & Yinjiang & HongDu River, Ge Lao Culture Tourist site \\
\hline \multirow{5}{*}{ Zunyi } & Wuchuan & Sea of Teas Ecological Park, "One in the world pot” Tea Culture park \\
\cline { 2 - 3 } & Meitan & The \\
\hline
\end{tabular}

\section{Establishment of indicator system}

The tourism poverty alleviation aims to improve local economy through the development of tourism, and thus improve the living conditions of residents. As for the output indicator system, the per capita disposable income of urban residents and the per capita net income of farmers are selected as the income reflects the living standard of the residents. As for the input indicator system, indicators that can show the degree of tourism development should be selected. The comprehensive tourism income can reflect the achievements of the tourism industry, and the number of tourist can reflect the attractiveness of the region. Therefore, the input indicator system is constituted by the per capita tourism comprehensive income and per capita tourist receptions, because of the need to balance the input indicators with the output indicators. The original data of 12 districts of Wuling Mountain Area of Guizhou Province from 2013 to 2016 comes from the statistical communique of the national economic and social development, the Report on the Work of the Government and Guizhou Statistical Yearbook. In this study, the number of DMUs is 12 , and the number of indicators is 4 , which meets the requirement of DEA model that the number of DMUs is supposed to be more than twice the number of indicators.

\section{EMPIRICAL ANALYSIS}

\section{A. Total efficiency analysis}

Based on the DEC-CCR model, the tourism poverty alleviation efficiency of districts in Wuling Mountain Area of Guizhou from 2013 to 2016 was calculated by deap2.1. The results are shown in Table 2 .
TABLE II. TOTAL EFFICIENCY OF TOURISM POVERTY ALLEVIATION IN WULING MOUNT AIN AREA OF GUIZHOU

\begin{tabular}{|c|c|c|c|c|c|}
\hline District & $\mathbf{2 0 1 3}$ & $\mathbf{2 0 1 4}$ & $\mathbf{2 0 1 5}$ & $\mathbf{2 0 1 6}$ & Mean \\
\hline Shiqian & 0.449 & 0.404 & 0.413 & 0.437 & 0.426 \\
\hline Bijiang & 0.305 & 0.294 & 0.287 & 0.318 & 0.301 \\
\hline Sinan & 0.682 & 0.680 & 0.663 & 0.657 & 0.671 \\
\hline Wanshan & 1.000 & 1.000 & 1.000 & 1.000 & 1.000 \\
\hline Songtao & 0.614 & 0.568 & 0.581 & 0.591 & 0.589 \\
\hline Yuping & 0.269 & 0.318 & 0.292 & 0.324 & 0.301 \\
\hline Jiangkou & 0.139 & 0.117 & 0.125 & 0.152 & 0.133 \\
\hline Dejiang & 1.000 & 1.000 & 1.000 & 1.000 & 1.000 \\
\hline Yanhe & 0.574 & 0.539 & 0.550 & 0.539 & 0.551 \\
\hline Yinjiang & 0.350 & 0.328 & 0.331 & 0.357 & 0.342 \\
\hline Wuchuan & 1.000 & 1.000 & 1.000 & 1.000 & 1.000 \\
\hline Meitan & 0.921 & 1.000 & 0.982 & 0.968 & 0.968 \\
\hline Mean & 0.609 & 0.604 & 0.602 & 0.612 & 0.607 \\
\hline
\end{tabular}

Overall, the total efficiency of tourism poverty alleviation in the Wuling Mountain Area of Guizhou was 0.607, better than the average. From 2013 to 2016, it at first declined but rose afterward. This was a process of exploration where the allocation of resources became better later, which was inseparable from the local governments' full understanding of tourism resources in all areas. However, the overall efficiency of tourism poverty alleviation was uneven among different regions. Jiangkou had the lowest total poverty alleviation efficiency in tourism every year, and its average efficiency in the past 4 years was only 0.133 . By contrast, Wanshan, Dejiang and Wuchuan had gained DEA effectiveness for 4 successive years. Due to the differences in tourism resources in different regions, the effect of tourism on poverty alleviation varied. In addition, the tourism poverty alleviation work in Wuling Mountain Area of Guizhou needs improvement as the total efficiency of tourism poverty alleviation in Shiqian, 
Bijiang, Songtao, Yuping, Jiangkou and Yanhe was lower than the average level of Wuling Mountain Areas in Guizhou.

\section{B. Decomposition efficiency analysis}

The total efficiency can be decomposed into two parts: pure technical efficiency and scale efficiency. Pure technical efficiency and scale efficiency are interrelated to each other but jointly contribute to total efficiency. Based on the DEA-BCC model, the pure technical efficiency and the scale efficiency can be calculated by using the deap2.1.

\section{1) Pure technical efficiency analysis}

Pure technical efficiency measure depicts the distance between the actual production point and the production possibility curve under the assumption of optimal production scale, which caused by system and management. It mainly reflects whether the way of tourism poverty alleviation is reasonable. If the pure technical efficiency is equal to 1 , it means that with the current technical level, the allocation of tourism resources is reasonable and will have certain good effects on poverty alleviation. The evaluation of the pure technical efficiency of tourism poverty alleviation in Wuling Mountain Area of Guizhou is shown in Table 3.

TABLE III. PURE TECHNICAL EFFICIENCY OF TOURISM POVERTY ALLEVIATION IN WULING MOUNT AIN AREA OF GUIZHOU

\begin{tabular}{|c|c|c|c|c|c|}
\hline District & $\mathbf{2 0 1 3}$ & $\mathbf{2 0 1 4}$ & $\mathbf{2 0 1 5}$ & $\mathbf{2 0 1 6}$ & Mean \\
\hline Shiqian & 0.471 & 0.412 & 0.426 & 0.447 & 0.439 \\
\hline Bijiang & 1.000 & 1.000 & 1.000 & 1.000 & 1.000 \\
\hline Sinan & 0.695 & 0.694 & 0.686 & 0.671 & 0.687 \\
\hline Wanshan & 1.000 & 1.000 & 1.000 & 1.000 & 1.000 \\
\hline Songtao & 0.625 & 0.586 & 0.604 & 0.606 & 0.605 \\
\hline Yuping & 1.000 & 1.000 & 1.000 & 1.000 & 1.000 \\
\hline Jiangkou & 0.147 & 0.118 & 0.127 & 0.154 & 0.137 \\
\hline Dejiang & 1.000 & 1.000 & 1.000 & 1.000 & 1.000 \\
\hline Yanhe & 0.588 & 0.546 & 0.569 & 0.553 & 0.564 \\
\hline Yinjiang & 0.361 & 0.339 & 0.347 & 0.371 & 0.355 \\
\hline Wuchuan & 1.000 & 1.000 & 1.000 & 1.000 & 1.000 \\
\hline Meitan & 1.000 & 1.000 & 1.000 & 1.000 & 1.000 \\
\hline Mean & 0.741 & 0.725 & 0.730 & 0.734 & 0.732 \\
\hline
\end{tabular}

It can be seen from Table 3 that the average of pure technical efficiency of tourism poverty alleviation in Wuling Mountain Area of Guizhou from 2013 to 2016 was 0.732, which was at an upper-middle level. Overall, the methods of tourism poverty alleviation there was reasonable, and its system and management were effective. However, the annual average pure technical efficiencies of tourism poverty alleviation in the Wuling Mountain Area of Guizhou were in a state of flux, indicating that the local tourism poverty alleviation was significantly affected by the system and management. Bijiang, Wanshan, Yuping, Dejiang, Wuchuan and Meitan had been purely technically effective for four successive years, indicating that at the current level of technology, these regions had reasonable tourism resources configuration. The pure technical efficiency of Shiqi, Jiangkou and Yinjiang were below 0.5, indicating that the technology promotion in these areas was inadequate and poor. Combined with the results in Table 2, the total efficiency of tourism poverty alleviation in Bijiang, Yuping and Meitan were DEA ineffective, but the pure technical efficiency there was effective. It may be said that the scale of investment in tourism resources in these areas were not optimal.

\section{1) Scale efficiency analysis}

Scale efficiency refers to the gap between the current scale and the optimal one under certain conditions, reflecting the efficiency of the scale of tourism on economic poverty alleviation. Increasing returns to scale means that the proportion of increase in output is greater than that of the increase in input, indicating that the investment in tourism is insufficient, and scaling up can increase productivity. Conversely, declining returns to scale means that tourism investment is redundant, and scaling down can increase productivity. When the scale efficiency is equal to 1 , the scale return is unchanged, indicating that the factor input of tourism poverty alleviation has reached the optimal scale. The evaluation of the scale of tourism poverty alleviation in the Wuling Mountain Area of Guizhou is shown in Table 4.

TABLE IV. SCALE EFFICIENCY OF TOURISM POVERTy ALLEVIATION IN WUling MOUNT Ain AREA OF GUIZHOU

\begin{tabular}{|c|c|c|c|c|c|c|c|c|}
\hline \multirow[b]{2}{*}{ District } & \multicolumn{2}{|c|}{2013} & \multicolumn{2}{|c|}{2014} & \multicolumn{2}{|c|}{2015} & \multicolumn{2}{|c|}{2016} \\
\hline & $\begin{array}{c}\text { Scale } \\
\text { efficiency }\end{array}$ & $\begin{array}{l}\text { Return to } \\
\text { scale }\end{array}$ & $\begin{array}{c}\text { Scale } \\
\text { efficiency }\end{array}$ & $\begin{array}{l}\text { Return to } \\
\text { scale }\end{array}$ & $\begin{array}{c}\text { Scale } \\
\text { efficiency }\end{array}$ & $\begin{array}{l}\text { Return to } \\
\text { scale }\end{array}$ & $\begin{array}{c}\text { Scale } \\
\text { efficiency }\end{array}$ & $\begin{array}{l}\text { Return to } \\
\text { scale }\end{array}$ \\
\hline Shiqian & 0.954 & drs & 0.981 & irs & 0.969 & irs & 0.977 & irs \\
\hline Bijiang & 0.305 & drs & 0.294 & drs & 0.287 & drs & 0.318 & drs \\
\hline Sinan & 0.981 & drs & 0.979 & irs & 0.968 & irs & 0.979 & irs \\
\hline Wanshan & 1.000 & - & 1.000 & - & 1.000 & - & 1.000 & - \\
\hline Songtao & 0.983 & drs & 0.969 & irs & 0.962 & irs & 0.976 & irs \\
\hline Yuping & 0.269 & drs & 0.318 & drs & 0.292 & drs & 0.324 & drs \\
\hline Jiangkou & 0.942 & drs & 0.995 & irs & 0.982 & irs & 0.988 & irs \\
\hline Dejiang & 1.000 & - & 1.000 & - & 1.000 & - & 1.000 & - \\
\hline Yanhe & 0.976 & drs & 0.989 & irs & 0.966 & irs & 0.973 & irs \\
\hline Yinjiang & 0.970 & drs & 0.966 & irs & 0.955 & irs & 0.962 & irs \\
\hline Wuchuan & 1.000 & - & 1.000 & - & 1.000 & - & 1.000 & - \\
\hline Meitan & 0.921 & drs & 1.000 & - & 0.982 & drs & 0.968 & drs \\
\hline Mean & 0.858 & & 0.874 & & 0.864 & & 0.872 & \\
\hline
\end{tabular}

Note: "irs" stands for increasing returns to scale; "drs" stands for decreasing returns to scale, "_" stands for unchanged returns to scale

It can be seen from Table 4 that the average scale efficiency of tourism poverty alleviation in the Wuling Mountain Area of Guizhou from 2013 to 2016 was 0.867, which was at an upper-middle level. The annual averages were $0.858,0.874$, 0.864 and 0.872 , respectively, which was relatively stable with little change. The scale efficiency of some districts (Wanshan, Dejiang, Wuchuan) had been in the same stage of constant returns to scale, indicating there had optimum the scale of development of local tourism and the reasonable proportion of factor inputs. The scale efficiency of several districts (Shiqian, 
Sinan, Songtao, Jiangkou, Yanhe, Yinjiang) were in the increasing stage of scale returns, indicating that the development of tourism in these areas had a significant effect on economic poverty alleviation. But the scale of tourism development in these areas still has room for further expansion. If expand investment in tourism resources, the efficiency of tourism poverty alleviation can be improved. Bijiang and Yuping had reducing returns to scale, indicating that there was redundancy in tourism investment in these two places. Excessive expansion of tourism scale did not play an important part in poverty alleviation. Therefore, tourism resources can be appropriately reduced to save costs.

2) The relationship between total efficiency and pure technical efficiency and scale efficiency

According to the mean value of total efficiency, pure technical efficiency and scale efficiency of tourism poverty alleviation in Wuling Mountain Area of Guizhou from 2013 to 2016, a scatter diagram of total efficiency and pure technical efficiency and a scatter diagram of total efficiency and scale efficiency are produced respectively (Fig. 1). They can reflect the contribution of decomposition efficiency to total efficiency.

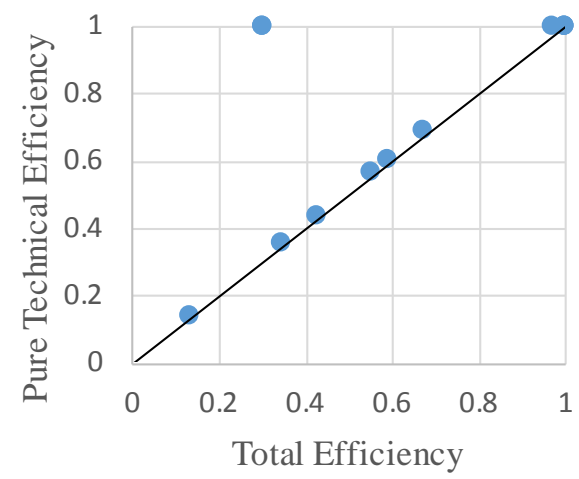

(a) Total efficiency - Pure technical efficiency

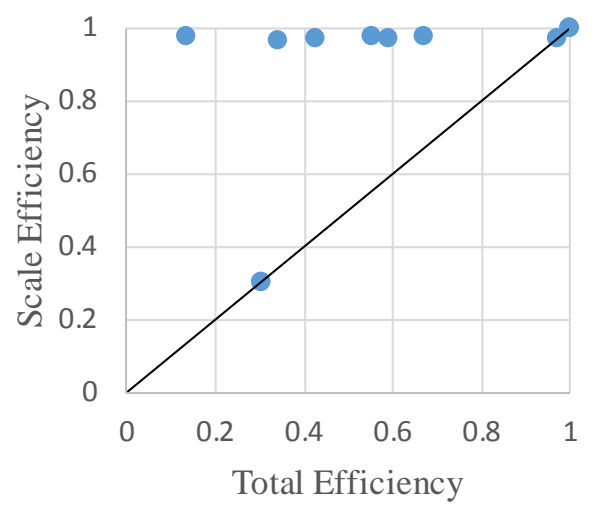

(b) Total efficiency - Scale efficiency

Fig. 1. Scatter diagrams of total efficiency and pure technical efficiency, total efficiency and scale efficiency

In Fig. 1, the abscissas are the total efficiency, and the ordinates are pure technical efficiency and scale efficiency, respectively. In general, the dot is closer to the diagonal, the efficiency has more contribution to the overall efficiency. It can be seen from diagrams (a) and (b) that the scatter dots of tourism poverty alleviation efficiency are not completely matched with the 45-degree diagonal, so the total efficiency of tourism poverty alleviation was affected by purely technical and scale efficiency. In diagram (a), most of the scatters are near the 45-degree diagonal. While in diagram (b), only a small number of scatters are on the 45-degree diagonal, and other scatters are at the top of the scatter plot. These phenomena are consistent with the result that the overall mean of scale efficiency was greater than that of pure technical efficiency. Therefore, pure technical efficiency contributed more to total efficiency than scale efficiency. If we want to improve the efficiency of tourism poverty alleviation, we should focus on enhancing the pure technical efficiency, increase the technical promotion of tourism and improve systems and management.

\section{CONCLUSION AND SUGGESTION}

\section{A. Conclusion}

This paper uses the DEA model to measure the tourism poverty alleviation efficiency of 12 districts in Wuling Mountain Area of Guizhou from 2013 to 2016. From the total efficiency, pure technical efficiency and scale efficiency, the following conclusions can be drawn.

Firstly, the average efficiency of tourism poverty alleviation in the Wuling Mountain Area of Guizhou from 2013 to 2016 was 0.607 , which was at an upper-middle level. However, due to the differences in tourism resources in various regions, the overall efficiency of tourism poverty alleviation was unevenly distributed, and the total efficiency of every district differed a lot. Among them, Wanshan, Dejiang and Wuchuan had higher total efficiency of tourism poverty alleviation, and all of them are effective in DEA. Wanshan actively explored the "tourism+" model, focusing on the cultural tourism industry, and enjoyed the support of the State Council's policy for resource-exhausted city. Dejiang's 'Nuo Culture" attracted countless tourists from home and abroad, and Fengxiangxi Conference site and other "Red Culture" made Dejiang become a popular red tourist destination. Wuchuan was the only well-preserved Gelao ethnic culture village in the country, which increased tourism appeal by its unique culture. Therefore, the development of tourism in these areas has greatly contributed to the poverty alleviation. Jiangkou had the lowest efficiency of tourism poverty alleviation because tourism poverty alleviation there started earlier than that in other districts. The tourism poverty alleviation stagnated so its effect was not as good as that of other districts where tourism poverty alleviation just begun.

Secondly, the average pure technical efficiency was 0.732 , and the average scale efficiency was 0.867 . They were above average. All these good achievements were due to the efforts of promoting poverty alleviation in tourism and expanding the scale of the tourism industry by Guizhou Province. However, returns to scale of Yuping and other places were on the decreasing, showing that the local tourism-related resources were improperly utilized and there was redundancy in investments. Blindly expanding the scale of tourism has not fueled the economic poverty alleviation. From the contribution of decomposition efficiency to total efficiency, total efficiency was more constrained by pure technical efficiency. The pure technical efficiency was generally lower than the scale 
efficiency and the low pure technical efficiency was the main reason for the poor performance of the total efficiency, therefore, improving the pure technical efficiency is the key to improving the efficiency of tourism poverty alleviation.

\section{B. Suggestion}

On the one hand, establish a training system for tourism practitioners. Due to the constraints of resources and conditions, governments in poverty-stricken areas often overlook the personnel training mechanism, the employees do not have a good education and professional quality. As an important part of the modern service industry, tourism has high requirements for the service awareness, reception capacity and tourism common sense of relevant practitioners. Most of the rural tourism workers are farmers with lower education levels, which restrict the development of local tourism to a certain extent. Therefore, local governments should establish effective personnel training mechanism, popularize local cultural common sense, and enhance residents' participation in tourism poverty alleviation. They could also conduct professional training for tourism practitioners on service awareness and reception capacity so as to comprehensively improve the utilization rate of talents and promote the tourism poverty alleviation.

On the other hand, optimize the management system. Wuling Mountain Area of Guizhou boasts rich tourism resources and has good basic conditions for tourism poverty alleviation. Therefore, the utilization efficiency of these resources has become a critical issue. From the empirical results of this paper, the efficiency of tourism poverty alleviation in Wuling Mountain Area of Guizhou mainly depends on the pure technical efficiency. However, Yinjiang and other districts had relatively low pure technical efficiency. Therefore, local governments should perfect the management system and increase the utilization efficiency of tourism investment. The following are specific measures which can be considered. First, make detailed plans for tourism poverty alleviation in accordance with the type of tourism resources in the jurisdiction to avoid homogenization competition. Second, clarify the responsibility and division of labor for each department to avoid the duplication or omission of work content. Third, supervise the tourism development market, securing both the economic benefits and the social benefits of tourism poverty alleviation, and avoiding the loss of long-term interest by blind developed tourism projects.

\section{REFERENCES}

[1] Bennett O, Roe D, Ashley C, "Sustainable Tourism and Poverty Elimination Study,” J. Overseas Development Institute, 1999

[2] Huang Meifang, Yu Yuchun, "National Touris m Poverty Alleviation Performance Evaluation Index System and Empirical Study,” J. Journal of Guilin University of Technology, vol 34, pp. 406-410, May 2014. (In Chinese)

[3] Feng Weilin, Tao Congchong, "On the Performance Evaluation of Tourism Poverty Alleviation in Southwest Ethnic Regions-Taking the Wuling Mountain Area in Chongqing as the Survey, J. Chinese Journal of Agricultural Resources and Regional Planning, vol 38, pp. 157-163, June 2017. (In Chinese)

[4] Huang Yuanji, "Evaluation of Touris m Poverty Alleviation Efficiency in Contiguous Poverty-stricken Areas and Space-time Differentiation Taking 20 Counties (cities, districts) in Wuling Mountain Hunan Area as an Example," J. Economic Geography, vol 37, pp. 229-235, November 2017. (In Chinese)

[5] Long Zukun, Du Qianwen, Zhou Ting, "Time Evolution and Spatial Differentiation of Tourism Poverty Alleviation Efficiency in Wuling Mountain Area,” J. Economic Geography, vol 35, pp. 210-217, October 2015. (In Chinese)

[6] Geng Changwei, Duan Zhengliang, Zeng Meiyan, "Evaluation of Tourism Poverty Alleviation Efficiency in Liupanshan Area Based on DEA Model,” J. Journal of Central South University of Forestry \& Technology (Social Sciences), vol 12, pp. 57-64, February 2018. (In Chinese) 